\title{
Práticas Educativas de Pais e Mães de Crianças aos 18 Meses de Idade $^{1}$
}

\author{
Cesar Augusto Piccinini ${ }^{2}$ \\ Giana Bitencourt Frizzo \\ Universidade Federal do Rio Grande do Sul \\ Patrícia Alvarenga \\ Universidade Federal da Bahia \\ Rita Sobreira Lopes \\ Universidade Federal do Rio Grande do Sul \\ Jonathan Tudge \\ University of North Carolina at Greensboro
}

\begin{abstract}
RESUMO - O presente estudo investigou eventuais diferenças nas práticas educativas de mães e pais de crianças de 18 meses de idade. Participaram 34 famílias de diferentes níveis socioeconômicos que tinham um único filho(a). As mães e os pais responderam separadamente a uma entrevista sobre práticas educativas envolvendo seis situações do dia-a-dia da criança. Análise de conteúdo revelou uma predominância de práticas indutivas relatadas tanto pelas mães como pelos pais, seguidas de práticas coercitivas e de não-interferência. Contudo, não houve diferença significativa entre as práticas mencionadas pelas mães e pais, nem entre os diferentes níveis socioeconômicos, em nenhuma das categorias examinadas. Os resultados são discutidos considerando-se as repercussões do surgimento da assertividade e da fase inicial do desenvolvimento da linguagem em que se encontravam as crianças sobre as práticas educativas parentais.
\end{abstract}

Palavras-chave: práticas educativas; família; criança.

\section{Mothers' and Fathers' Educative Practices with their 18-Month-Old Children}

\begin{abstract}
The present study investigated eventual differences in educative practices of mothers and fathers of 18-month-old children. Thirty-four families of different socioeconomic levels who had only one child took part in the study. The mothers and fathers answered separately an interview on educative practices involving six daily situations of the child. The content analysis revealed a predominance of inductive practices reported both by mothers and fathers, followed by coercitive and non-interference practices. However, no significant differences were found between the practices mentioned by mothers and fathers, or between the different socioeconomic levels in none of the examined categories. The results are discussed taking into consideration the repercussions of the appearance of assertiveness and of the initial phase of language development of the children on parental educative practices.
\end{abstract}

Key words: educative practices; family; child.

Socialização é o processo através do qual adquirimos comportamentos, crenças e atitudes que são usados em diferentes contextos sociais (Durkin, 1995). Este processo tem início desde que o bebê nasce, e muitas investigações têm sugerido que a história de interação da criança com seus cuidadores durante os primeiros anos é a base para o sucesso em suas futuras relações com os pares (Raver, 1996). Para

1 Gostaríamos de agradecer ao CNPq e a Spencer Foundation (financiamento ao último autor) pelo auxílio financeiro recebido. $\mathrm{O}$ último autor gostaria de agradecer o convite do PPG-Psicologia da UFRGS para ser Professor Visitante durante um ano, financiado pela CAPES e, à Universidade da Carolina do Norte em Greensboro pela liberação do referido professor.

2 Endereço: Instituto de Psicologia, UFRGS, Rua Ramiro Barcelos, 2600, sala 111, Porto Alegre, RS, Brasil 90035-003. E-mail: piccinini@portoweb.com.br cumprir esse papel junto aos filhos, os pais utilizam-se de diversas estratégias para orientar seus comportamentos. Essas estratégias de socialização utilizadas pelos pais são denominadas por alguns autores de práticas educativas parentais (Grusec \& Lytton, 1988; Mussen, Conger, Kagan \& Huston, 1990; Newcombe, 1999).

O conjunto de práticas educativas utilizadas pelos pais pode ser dividido em duas categorias distintas: as práticas indutivas e as práticas coercitivas. Para Hoffman $(1975,1994)$ a estratégia indutiva caracteriza-se por atingir o objetivo disciplinar indicando para a criança as consequiências do seu comportamento para as outras pessoas e chamando sua atenção para os aspectos lógicos da situação. Isso propicia à criança a compreensão das implicações de suas ações e, portanto, dos motivos que justificam a necessidade de mudança no seu comportamento. Desta forma, a criança desenvolve certa autonomia para utilizar esse tipo de informação para controlar seu próprio comportamento. Como exemplos desse 
tipo de estratégia pode-se citar o uso de explicações sobre o comportamento da criança e as suas conseqüências e explicações a respeito de regras, princípios e valores (Hart, Ladd \& Burleson, 1990; Hoffman, 1991, 1994).

Já as estratégias de força coercitiva caracterizam-se, segundo Hoffman (1975), pela aplicação direta da força, incluindo punição física, privação de privilégios e afeto ou pelo uso de ameaças dessas atitudes. Essas técnicas fazem com que a criança controle seu comportamento em função das reações punitivas dos pais. Além disso, elas produzem emoções intensas tais como medo, raiva e ansiedade, que tendem a reduzir ainda mais a possibilidade de a criança compreender a situação e a necessidade de modificação de comportamento. Ou seja, o controle do comportamento da criança tenderá a depender de intervenções externas porque ela não adquire a capacidade de compreender as implicações de suas ações. Nesse sentido, as estratégias de força coercitiva não favorecem a internalização das regras sociais e padrões morais. Além de não contribuir para a aquisição de padrões adequados de comportamento, o uso frequiente de estratégias coercitivas tende a fazer com que crianças comportem-se de forma coercitiva com seus pares (Hart \& cols., 1990).

Três estudos brasileiros revelaram que as práticas indutivas tendem a ser mais utilizadas por mães de pré-escolares, do que as práticas coercitivas. Piccinini, Castro, Alvarenga, Vargas e Oliveira (2003) verificaram esta tendência comparando mães de crianças portadoras de doença crônica e mães de crianças sem problemas de saúde. Em ambos os grupos as práticas indutivas foram mais freqüentes. A mesma tendência foi verificada por Alvarenga e Piccinini (2003) em uma pesquisa que comparou a interação mãe-criança em díades com crianças que apresentavam problemas de externalização e díades cujas crianças não apresentavam problemas comportamentais. Nessa investigação, as mães dos dois grupos analisados apresentaram frequiências médias de práticas indutivas superiores àquelas referentes às práticas coercitivas. Contudo o estudo de Alvarenga e Piccinini (2001) que avaliou as práticas educativas maternas através de uma entrevista estruturada que abordava comportamentos inadequados específicos apresentados pelas crianças, encontrou uma frequiência superior de práticas indutivas apenas entre as mães de crianças sem problemas de comportamento. No grupo de crianças que apresentavam problemas de externalização, predominaram as práticas coercitivas.

Vários estudos indicam que as práticas educativas utilizadas por mães e pais com seus filhos passam por mudanças significativas ao longo do desenvolvimento da criança. $\mathrm{O}$ surgimento da assertividade na criança, por exemplo, tende a provocar profundas modificações nos tipos de estratégias utilizadas em situações de conflito. A assertividade permitirá à criança negociar sua independência no contexto das expectativas e exigências do mundo social. Ela pode ser definida como a habilidade de atingir os próprios objetivos, sem violar a integridade dos objetivos do outro (Crockenberg \& Litman, 1990). É a capacidade de defender os próprios direitos e de expressar pensamentos, sentimentos e crenças de forma honesta, direta e apropriada, sem violar os direitos da outra pessoa (Falcone, 2001). É em torno dos dois anos de idade que a criança começa a desenvolver o comportamento assertivo e uma das aquisições mais importantes para o desenvolvimento desta habilidade é a capacidade de dizer "não". Kuczynski, Kochanska, RadkeYarrow e Girnius-Brown (1987) constataram que crianças que diziam "não" com maior freqüência, se engajavam em mais negociações com suas mães. À medida que a criança começa a demonstrar assertividade, as práticas educativas parentais devem acomodar-se a essa nova aquisição no repertório infantil. Diante de um comportamento assertivo da criança, como a recusa em atender alguma ordem ou pedido, as atitudes parentais tendem a se alterar. Por exemplo, a mãe poderá explicar à criança porque ela deve cooperar, tentar persuadi-la tornando a tarefa atrativa, ou ainda abandonar seu objetivo em favor de alguma outra alternativa que a criança pareça aceitar melhor (Crockenberg \& Litman, 1990).

Outros estudos corroboram a hipótese de que o período de desenvolvimento no qual a criança se encontra desempenha um papel importante na determinação das práticas educativas (McNally, Eisenberg \& Harris, 1991; Roberts, Block \& Block, 1984). O uso de punição física, por exemplo, diminui à medida que a criança cresce, ao mesmo tempo que demonstrações físicas de afeto também diminuem, sendo substituídas por outras formas de expressão de aprovação e afeto. Além disso, à medida que a criança vai adquirindo domínio sobre a linguagem, os pais podem fazer maior uso de orientações verbais e explicações racionais (Mussen \& cols., 1990). A atribuição de maior ou menor competência e responsabilidade à criança por parte da mãe, também parece mediar as variações nas estratégias disciplinares utilizadas (Dix, Ruble \& Zambarano, 1989).

Além desses fatores, outra variável que tem sido apontada como um possível preditor das práticas educativas parentais é o sexo do genitor. No entanto, as diferenças entre práticas educativas maternas e paternas têm sido pouco exploradas, especialmente em crianças pequenas.

Investigações sobre as diferenças nos padrões de interação de pais e mães com seus filhos indicam que enquanto os pais tendem a adotar modalidades de interação que envolve predominantemente a estimulação física e movimentos mais fortes, como saltar, correr e jogar a criança para cima, as mães tendem a ser mais delicadas e utilizariam mais brinquedos e a interação verbal, além de participarem mais nas tarefas de cuidados (Parke, 1981; Schaffer, 1996). O estudo de Belsky (1979), que comparou padrões de interação de pais e mães de crianças de 15 meses de idade, confirmou a tendência das mães ao maior envolvimento nos cuidados com a criança, mas não constatou diferenças expressivas entre pais e mães nas demais modalidades de interação, com exceção da categoria estimulação, que foi mais freqüente entre as mães. Entretanto, as mães revelaram estar mais envolvidas na criação dos filhos do que os pais, o que explica em parte, o grande número de estudos realizados apenas com as mães, não incluindo o relato paterno (Alvarenga \& Piccinini, 2001; Chen \& cols, 1998; Fox, Platz \& Bentley, 1995; McNally \& cols., 1991; Piccinini \& cols., 2003; Tudge, Hayes \& cols, 2000). Contudo, o fato de as mães se envolverem mais nos cuidados com os filhos não significa que os pais sejam menos hábeis para desempe- 
nhar esse tipo de tarefa. Parke (1981) verificou que os pais foram tão competentes quanto as mães ao identificar e responder aos sinais de suas crianças realizando a tarefa de alimentá-las.

As diferenças encontradas nos padrões de comportamento que pais e mães adotam ao interagir com seus filhos, sugerem que diferenças semelhantes possam ocorrer nas práticas educativas parentais. Contudo, os estudos abordando esta problemática são escassos e os resultados apontam para diferentes direções. Por exemplo, o estudo de Bentley e Fox (1991) comparou os estilos parentais de pais e mães de crianças de 1 a 4 anos, e as respostas dos participantes a um questionário estruturado indicaram não haver diferenças significativas entre as estratégias empregadas pelos pais e pelas mães. Nesta mesma perspectiva, o estudo de Cia, Pereira, Del Prette e Del Prette (2006) também não constatou diferenças ao comparar o envolvimento de pais e mães de crianças da primeira série do ensino fundamental. Por outro lado, Baker e Heller (1996) que realizaram um estudo com o objetivo de comparar os estilos parentais de pais e mães em famílias com crianças com problemas de externalização, encontraram diferenças marcantes entre pais e mães. Os resultados revelaram que com crianças que apresentam esse tipo de problema de comportamento, os pais demonstraram um estilo mais autoritário e menos indulgente e permissivo, bem como maior indiferença e menor envolvimento com os filhos quando comparados às mães.

A influência do nível socioeconômico sobre as práticas educativas parentais também tem sido investigado, e nesse caso, alguns estudos da década de 1990 indicam de forma consistente que quanto mais baixo o nível socioeconômico, maior a frequiência de práticas coercitivas. Fox e cols. (1995) verificaram que mães com nível sócio-econômico e educacional baixo tendiam a empregar um menor número de estratégias educacionais e disciplinares não-coercitivas. Os estudos de Booth, Rose-Krasnor e Rubin (1991) e Dodge, Pettit e Bates (1994) também revelaram que o nível socioeconômico correlaciona-se negativamente com o uso de práticas coercitivas. Contudo, um estudo recente, conduzido por Roopnarine, Fouts, Lamb e Lewis-Elligan (2005) mostrou que, apesar das inúmeras evidências acumuladas pela literatura nas últimas décadas que indicam os prejuízos no comportamento parental relacionados ao baixo nível socioeconômico, esta tendência não foi tão expressiva na amostra de pais e mães afroamericanos investigada no referido estudo. Os pais e mães de nível socioeconômico baixo foram tão responsivos e atentos às necessidades de afeto, conforto, alimentação e estimulação quanto os de níveis socioeconômico médio e alto. Porém, as mães de nível socioeconômico alto utilizavam mais estratégias verbais quando estavam confortando seus bebês, e tanto os pais quanto as mães de nível socioeconômico baixo seguravam mais seus filhos no colo do que os participantes dos outros dois grupos.

Considerando as tendências nos achados dos estudos revisados, bem como as lacunas que permanecem com relação ao processo de socialização no contexto familiar nos primeiros anos de vida, o objetivo do presente estudo foi investigar as práticas educativas parentais utilizadas com crianças de 18 meses de idade, examinando eventuais diferenças entre as práticas relatadas por pais e mães. Além disso, o estudo examinou a influência do nível socioeconômico da família sobre as práticas utilizadas.

\section{Método}

\section{Participantes}

Participaram do estudo 34 famílias com crianças de aproximadamente 18 meses. A idade média foi de 18,62 meses $(D P=0,82)$, sendo que 16 eram meninas e 18 eram meninos. As mães eram primíparas com idade média de 22 anos $(D P=5,90)$. A escolaridade média era de 10 anos $(D P=2,50)$. Os pais tinham idade média de 24 anos $(D P=6,63)$ e escolaridade média de nove anos $(D P=2,92)$. A maioria das mães vivia com o companheiro/marido $(91 \%)$ sendo que apenas três eram solteiras. As famílias eram de diferentes níveis socioeconômicos (NSE), de acordo com critérios baseados em Hollingshead (1975) adaptados para o presente estudo por Tudge e Frizzo (2002). Das 34 famílias participantes, nove (27\%) eram de NSE baixo, oito (23\%) médio-baixo, 11 (32\%) médio, quatro (12\%) médio-alto e duas $(6 \%)$ alto.

A amostra foi selecionada, com base nos critérios descritos acima, dentre os participantes do "Estudo Longitudinal de Porto Alegre: Da Gestação à Escola" (Piccinini, Lopes, Sperb \& Tudge, 1998) que teve por objetivo investigar tanto os aspectos subjetivos e comportamentais das interações iniciais pai-mãe-bebê, como o impacto de fatores iniciais do desenvolvimento nas interações familiares, no comportamento social de crianças pré-escolares e na transição para a escola de ensino fundamental. O estudo iniciou acompanhando 81 gestantes, que não apresentavam intercorrências clínicas, seja com elas mesmas ou com o bebê, que era seu primeiro filho. Os maridos ou companheiros, também foram convidados a participar do estudo caso residissem juntos em situação matrimonial. Os participantes representavam várias configurações familiares (nucleares, monoparentais ou recasados), de diferentes idades (adultos e adolescentes) e com escolaridade e níveis sócio-econômicos variado. Foram realizadas várias coletas de dados desde a gestação até os 7 anos das crianças (gestação, $3^{\circ}, 8^{\circ}, 12^{\circ}, 18^{\circ}, 24^{\circ}, 36^{\circ}$ meses e $6^{\circ}$ e $7 \stackrel{0}{ }$ ano de vida da criança). O convite inicial para participar do estudo ocorreu quando a gestante fazia pré-natal em hospitais da rede pública da cidade de Porto Alegre (51,2\%), nas unidades sanitárias de saúde do mesmo município $(7,3 \%)$, através de anúncio em veículos de comunicação $(26,8 \%)$ e por indicação $(14,6 \%)$. O estudo foi aprovado pelo Comitê de Ética da UFRGS.

\section{Delineamento e instrumentos}

Foi utilizado um delineamento de grupos contrastantes (Nachmias \& Nachmias, 1996) com vistas a comparar as eventuais diferenças entre as práticas educativas maternas e paternas aos 18 meses da criança.

Para fins de coleta de dados foram utilizados os seguintes instrumentos. Ficha de dados demográficos (GIDEP, 1998): esta ficha foi preenchida pelas mães, ainda na gestação, com o auxílio dos pesquisadores que participaram da primeira fase de coleta de dados do estudo, com o objetivo de investigar 
alguns dados demográficos, tais como idade da mãe e do companheiro, escolaridade, profissão, estado civil, e existência de outros filhos. Entrevista sobre práticas educativas parentais (Piccinini\& Alvarenga, 2001): esta entrevista estruturada foi aplicada quando o bebê estava com 18 meses. Era composta de seis situações que comumente ocorrem no dia-a-dia das crianças e envolvem comportamentos inadequados ou desobediência da criança, a saber: a) a criança recusa-se a comer; b) a criança recusa-se a ficar com outra pessoa; c) a criança recusa-se a trocar de roupa; d) a criança recusa-se a dormir à noite; e) a criança recusa-se a entrar/sair do banho; e, f) a criança faz birra quando recebe um não. Após o relato de cada situação, eram investigadas as práticas educativas utilizadas pelas mães e pais. Esta entrevista foi realizada separadamente para a mãe e o pai, tendo sido gravadas em audiotape e posteriormente transcritas para análise.

\section{Resultados}

Análise de conteúdo (Laville \& Dionne, 1999) foi utilizada para se examinar as práticas educativas relatadas pelas mães e pais nas diversas situações investigadas na entrevista descrita acima. Para fins de análise foram utilizadas as categorias propostas por Alvarenga e Piccinini, (2001), baseada em Hoffman $(1975,1979,1991,1994)$, que propõe a análise das práticas educativas parentais em duas categorias: Práticas educativas indutivas e Práticas educativas coercitivas. No entanto, tendo em vista a necessidade de considerar algumas especificidades entre o presente estudo, com crianças de 18 meses e o estudo de Alvarenga e Piccinini (2001) com crianças de 5 anos, foi necessária a criação de uma terceira categoria, denominada Não-interferência. Além disto, algumas estratégias educativas não puderam ser enquadradas nas categorias anteriores e foram denominadas Outras. A definição das categorias encontra-se no Anexo A. Cada categoria foi subdividida em algumas subcategorias (ver Tabela 1). Para fins de análise foram consideradas as três primeiras práticas educativas relatadas por cada mãe e pai. Como alguns participantes relataram o uso de apenas uma prática educativa, a fidedignidade foi calculada apenas sobre a primeira resposta relatada em cada uma das seis situações analisadas. $\mathrm{O}$ índice de fidedignidade entre os codificadores na classificação das práticas nas diversas categorias foi calculado utilizando-se o coeficiente Kappa em uma amostra de $20 \%$ das entrevistas e atingiu o valor médio de 0,74 , o que é considerado bom (Robson, 1993).

A Tabela 1 apresenta os percentuais e frequiências das respostas sobre as práticas educativas maternas aos 18 meses de vida da criança. Independente das situações, a maioria das práticas mencionadas foi classificada como indutivas (44\%), seguidas pelas práticas coercitivas $(31 \%)$ e nãointerferência (20\%).

Considerando as situações examinadas, alguns dados se destacaram. As práticas indutivas foram mencionadas com maior freqüência para quase todas as situações: dormir (58\%), ficar com pessoas (50\%), comer (47\%), banho (46\%) trocar de roupa (42\%), com exceção da situação de birra (29\%). Já as práticas coercitivas foram mais mencionadas nas situações de birra (54\%). A não-interferência foi mais mencionada na situação comer (36\%). Por fim, chama atenção que a situação ficar com pessoas, que se referia aos momentos em que as mães tinham que sair e deixavam a criança com um cuidador, foi muito associada à subcategoria enganar $(31 \%)$.

A Tabela 2 apresenta os percentuais e frequiências das respostas sobre práticas educativas paternas aos 18 meses de

Tabela 1. Freqüências e percentuais das respostas sobre práticas educativas maternas aos 18 meses da criança $(n=34)$.

\begin{tabular}{|c|c|c|c|c|c|c|c|}
\hline \multirow[b]{2}{*}{ Práticas educativas } & \multicolumn{7}{|c|}{ Situações } \\
\hline & Total & Comer & Ficar com pessoas & Trocar de roupa & Dormir & Banho & Birra \\
\hline Indutivas & $44 \%(126)$ & $47 \%(24)$ & $50 \%(13)$ & $42 \%(24)$ & $58 \%(25)$ & $46 \%(22)$ & $29 \%(18)$ \\
\hline Negocia e troca & $22 \%(64)$ & $36 \%(19)$ & $15 \%(4)$ & $14 \%(8)$ & $21 \%(9)$ & $33 \%(16)$ & $13 \%(8)$ \\
\hline Explica/ fala & $14 \%(40)$ & $8 \%(4)$ & $35 \%(9)$ & $25 \%(14)$ & $2 \%(1)$ & $6 \%(3)$ & $15 \%(9)$ \\
\hline Organiza ambiente & $4 \%(13)$ & - & - & - & $28 \%(12)$ & $2 \%(1)$ & - \\
\hline Comanda verbalmente sem coerção & $3 \%(10)$ & $4 \%(2)$ & - & $4 \%(2)$ & $7 \%(3)$ & $4 \%(2)$ & $2 \%(1)$ \\
\hline Coercitivas & $31 \%(90)$ & $15 \%(9)$ & - & $44 \%(25)$ & $19 \%(8)$ & $31 \%(15)$ & $54 \%(33)$ \\
\hline Pune verbalmente & $11 \%(31)$ & $2 \%(1)$ & - & $16 \%(9)$ & $7 \%(3)$ & $8 \%(4)$ & $23 \%(14)$ \\
\hline Ameaça & $2 \%(8)$ & $4 \%(2)$ & - & $5 \%(3)$ & - & - & $5 \%(3)$ \\
\hline Coage fisicamente & $11 \%(36)$ & $8 \%(4)$ & - & $16 \%(9)$ & $12 \%(5)$ & $23 \%(11)$ & $12 \%(7)$ \\
\hline Pune fisicamente & $5 \%(15)$ & $2 \%(1)$ & - & $7 \%(4)$ & - & - & $15 \%(9)$ \\
\hline Não-interferência & $20 \%(57)$ & $36 \%(19)$ & $12 \%(3)$ & $14 \%(8)$ & $23 \%(10)$ & $16 \%(8)$ & $15 \%(9)$ \\
\hline Não se intromete & $8 \%(22)$ & $13 \%(7)$ & $4 \%(1)$ & $4 \%(2)$ & $7 \%(3)$ & $4 \%(2)$ & $12 \%(7)$ \\
\hline Segue ritmo da criança & $6 \%(17)$ & $17 \%(9)$ & - & $5 \%(3)$ & $9 \%(4)$ & $2 \%(1)$ & - \\
\hline Cede à vontade da criança & $6 \%(18)$ & $6 \%(3)$ & $8 \%(2)$ & $5 \%(3)$ & $7 \%(3)$ & $10 \%(5)$ & $3 \%(2)$ \\
\hline Outras & $5 \%(14)$ & $2 \%(1)$ & $35 \%(9)$ & - & - & $6 \%(3)$ & $2 \%(1)$ \\
\hline Engana & $4 \%(11)$ & - & $31 \%(8)$ & - & - & $4 \%(2)$ & $2 \%(1)$ \\
\hline Deixa para outra pessoa & $1 \%(3)$ & $2 \%(1)$ & $4 \%(1)$ & - & - & $2 \%(1)$ & - \\
\hline Total & 287 & 53 & 25 & 57 & 43 & 48 & 61 \\
\hline
\end{tabular}


Tabela 2. Freqüências e percentuais das respostas sobre práticas educativas paternas aos 18 meses da criança $(n=31)$.

\begin{tabular}{|c|c|c|c|c|c|c|c|}
\hline \multirow[b]{2}{*}{ Práticas educativas } & \multicolumn{7}{|c|}{ Situações } \\
\hline & Total & Comer & Ficar com pessoas & Trocar de roupa & Dormir & Banho & Birra \\
\hline Indutivas & $43 \%(100)$ & $36 \%(17)$ & $47 \%(9)$ & $56 \%(22)$ & $44 \%(19)$ & $50 \%(19)$ & $30 \%(14)$ \\
\hline Negocia e troca & $22 \%(52)$ & $28 \%(13)$ & $26 \%(5)$ & $25 \%(10)$ & $12 \%(5)$ & $31 \%(12)$ & $15 \%(7)$ \\
\hline Explica/ fala & $13 \%(30)$ & $4 \%(2)$ & $21 \%(4)$ & $23 \%(9)$ & $7 \%(3)$ & $16 \%(6)$ & $13 \%(6)$ \\
\hline Organiza ambiente & $4 \%(10)$ & $2 \%(1)$ & - & $3 \%(1)$ & $19 \%(8)$ & - & - \\
\hline Comanda verbalmente sem coerção & $3 \%(8)$ & $2 \%(1)$ & - & $5 \%(2)$ & $7 \%(3)$ & $3 \%(1)$ & $2 \%(1)$ \\
\hline Coercitivas & $30 \%(71)$ & $22 \%(10)$ & - & $39 \%(15)$ & $20 \%(9)$ & $34 \%(13)$ & $51 \%(24)$ \\
\hline Pune verbalmente & $11 \%(25)$ & $13 \%(6)$ & - & $8 \%(3)$ & $9 \%(4)$ & $3 \%(1)$ & $23 \%(11)$ \\
\hline Ameaça & $3 \%(8)$ & $2 \%(1)$ & - & $8 \%(3)$ & - & $3 \%(1)$ & $6 \%(3)$ \\
\hline Coage fisicamente & $13 \%(31)$ & $7 \%(3)$ & - & $23 \%(9)$ & $9 \%(4)$ & $28 \%(11)$ & $9 \%(4)$ \\
\hline Pune fisicamente & $3 \%(7)$ & - & - & - & $2 \%(1)$ & - & $13 \%(6)$ \\
\hline Não-interferência & $21 \%(50)$ & $35 \%(16)$ & $43 \%(8)$ & $5 \%(2)$ & $28 \%(12)$ & $11 \%(4)$ & $17 \%(8)$ \\
\hline Não se intromete & $6 \%(14)$ & $11 \%(5)$ & $16 \%(3)$ & - & $7 \%(3)$ & $5 \%(2)$ & $2 \%(1)$ \\
\hline Segue ritmo da criança & $6 \%(14)$ & $11 \%(5)$ & $11 \%(2)$ & $5 \%(2)$ & $7 \%(3)$ & $3 \%(1)$ & $2 \%(1)$ \\
\hline Cede vontade da criança & $9 \%(22)$ & $13 \%(6)$ & $16 \%(3)$ & - & $14 \%(6)$ & $3 \%(1)$ & $13 \%(6)$ \\
\hline Outras & $6 \%(13)$ & $6 \%(3)$ & $11 \%(2)$ & $3 \%(1)$ & $7 \%(3)$ & $6 \%(3)$ & $2 \%(1)$ \\
\hline Engana & $3 \%(6)$ & $2 \%(1)$ & $11 \%(2)$ & - & $2 \%(1)$ & $5 \%(2)$ & - \\
\hline Deixa para outra pessoa & $3 \%(7)$ & $4 \%(2)$ & - & $3 \%(1)$ & $5 \%(2)$ & $3 \%(1)$ & $2 \%(1)$ \\
\hline Total & 234 & 46 & 19 & 40 & 43 & 39 & 47 \\
\hline
\end{tabular}

vida da criança. À semelhança do que foi verificado com as mães, a maioria das práticas mencionadas pelos pais foram as classificadas como indutivas (43\%), seguidas pelas práticas coercitivas (30\%) e não-interferência (21\%).

Quanto às situações examinadas, as práticas indutivas foram bastante mencionadas em todas as situações: trocar de roupa $(56 \%)$, banho (50\%), ficar com pessoas (47\%), dormir (44\%), comer (36\%), com exceção da situação de birra (30\%). As práticas coercitivas foram particularmente mencionadas na situação birra (51\%). Quanto à não-interferência, houve maior incidência nas situações: ficar com pessoas $(43 \%) \mathrm{e}$ comer (35\%). A fim de se investigar as eventuais diferenças nas práticas educativas relatadas pelas mães e pelos pais utilizou-se o teste não-paramétrico Wilcoxon (Siegel \& Castellan, 1988/2006). A Tabela 3 apresenta a incidência média, o desvio padrão e o nível de significância das práticas educativas maternas e paternas aos 18 meses de vida do bebê. Como pode ser visto, os resultados não revelaram nenhuma diferença significativa na incidência de cada uma das práticas educativas mencionadas pelas mães e pais.

Por fim buscou-se investigar possíveis diferenças nas práticas educativas relatadas pelas mães e pais relacionadas ao nível socioeconômico da família. As Tabelas 4 e 5 apresentam a distribuição das práticas educativas maternas e paternas, respectivamente, de acordo com o nível socioeconômico da família. Como pode ser visto, as freqüências das práticas educativas maternas e paternas não variaram em função do nível socioeconômico, apresentando uma incidência muito semelhante nos diferentes níveis. O teste qui-quadrado não

Tabela 3. Incidência média, desvio padrão e nível de significância das práticas educativas maternas e paternas aos 18 meses do bebê.

\begin{tabular}{llll}
\hline Práticas educativas & maternas $(\boldsymbol{n}=\mathbf{3 4})$ & paternas $(\boldsymbol{n}=\mathbf{3 1})$ & $\boldsymbol{p}<$ \\
\hline Indutivas & $3,71(2,15)$ & $3,23(2,26)$ & 0,48 \\
Coercitivas & $2,65(1,79)$ & $2,29(2,25)$ & 0,25 \\
Não-interferência & $1,61(1,30)$ & $1,96(1,64)$ & 0,54 \\
Outras & $0,47(0,71)$ & $0,52(0,81)$ & 0,87 \\
\hline
\end{tabular}

revelou diferenças significativas entre os diferentes níveis socioeconômicos.

\section{Discussão}

Os resultados do presente estudo revelaram uma predominância de práticas indutivas relatadas tanto pelas mães quanto pelos pais nas diferentes situações investigadas. Esta tendência já havia sido apontada por outros estudos com

Tabela 4. Percentuais e frequiências das respostas sobre práticas educativas maternas aos 18 meses de acordo com o nível socioeconômico da família segundo Hollingshead (1975) $(n=34)$.

\begin{tabular}{lcccccc}
\hline & $\mathbf{1}$ & $\mathbf{2}$ & $\mathbf{3}$ & $\mathbf{4}$ & $\mathbf{5}$ & Total \\
\cline { 2 - 7 } Práticas & $52 \%$ & $38 \%$ & $44 \%$ & $43 \%$ & $45 \%$ & $46 \%$ \\
indutivas & $(39)$ & $(27)$ & $(35)$ & $(18)$ & $(9)$ & $(128)$ \\
Práticas & $35 \%$ & $37 \%$ & $28 \%$ & $29 \%$ & $20 \%$ & $31 \%$ \\
coercitivas & $(26)$ & $(26)$ & $(22)$ & $(12)$ & $(4)$ & $(90)$ \\
Não- & $9 \%$ & $18 \%$ & $22 \%$ & $26 \%$ & $25 \%$ & $18 \%$ \\
interferência & $(7)$ & $(13)$ & $(17)$ & $(11)$ & $(5)$ & $(53)$ \\
Outras & $4 \%$ & $7 \%$ & $6 \%$ & $2 \%$ & $10 \%$ & $6 \%$ \\
& $(3)$ & $(5)$ & $(5)$ & $(1)$ & $(2)$ & $(16)$ \\
\hline \multirow{2}{*}{ Total } & 75 & 71 & 79 & 42 & 20 & 287 \\
\hline
\end{tabular}

Tabela 5. Percentuais e freqüências das respostas sobre práticas educativas paternas aos 18 meses de acordo com o nível socioeconômico da família segundo Hollingshead (1975) $(n=31)$.

\begin{tabular}{lcccccc}
\hline & $\mathbf{1}$ & $\mathbf{2}$ & $\mathbf{3}$ & $\mathbf{4}$ & $\mathbf{5}$ & Total \\
\cline { 2 - 7 } $\begin{array}{l}\text { Práticas } \\
\text { indutivas }\end{array}$ & $34 \%$ & $40 \%$ & $50 \%$ & $31 \%$ & $50 \%$ & $44 \%$ \\
Práticas & $36 \%$ & $(21)$ & $(40)$ & $(8)$ & $(10)$ & $(100)$ \\
coercitivas & $(20)$ & $\begin{array}{c}33 \% \\
(17)\end{array}$ & $\begin{array}{c}28 \% \\
(22)\end{array}$ & $\begin{array}{c}35 \% \\
(9)\end{array}$ & $\begin{array}{c}15 \% \\
(3)\end{array}$ & $\begin{array}{c}30 \% \\
(71)\end{array}$ \\
Não- & $23 \%$ & $23 \%$ & $\begin{array}{c}15 \% \\
\text { interferência }\end{array}$ & $\begin{array}{c}27 \% \\
(7)\end{array}$ & $\begin{array}{c}25 \% \\
(5)\end{array}$ & $\begin{array}{c}15 \% \\
(36)\end{array}$ \\
Outras & $7 \%$ & $4 \%$ & $7 \%$ & $7 \%$ & $10 \%$ & $11 \%$ \\
& $(4)$ & $(2)$ & $(6)$ & $(2)$ & $(2)$ & $(27)$ \\
\hline \multirow{2}{*}{ Total } & 56 & 52 & 80 & 26 & 20 & 234 \\
\hline
\end{tabular}


crianças entre 5 e 6 anos de idade (Alvarenga \& Piccinini, 2003; Piccinini \& cols., 2003).

De qualquer modo, assim como em outras investigações, as práticas coercitivas também foram mencionadas com bastante freqüência, o que mostra que mesmo em se tratando de crianças pequenas, a coerção representa uma importante estratégia de regulação do comportamento infantil. As práticas coercitivas foram mais mencionadas tanto pelas mães como pelos pais na situação de birra, possivelmente devido à aversividade deste comportamento para os pais. Nesse sentido, a prática coercitiva pode estar sendo utilizada com o objetivo de socialização de curto prazo, ou seja, interromper imediatamente o comportamento da criança, que precisa obedecer ao pai ou mãe (Newcombe, 1999; Saadeh, Rizzo \& Roberts, 2002; Weber, Viezzer \& Brandenburg, 2004).

Uma peculiaridade encontrada no presente estudo foram os relatos maternos e paternos que referiam a atitude de não interferir no comportamento da criança. A quantidade expressiva de relatos classificados nesta categoria poderia ser explicada pelo surgimento da assertividade nesta etapa do desenvolvimento infantil (Crockenberg \& Litman, 1990). A opção por não intervir adotada pelos pais e mães em várias das situações investigadas, pode ser atribuída a diferentes razões. Uma delas é um possível estado de perplexidade diante desta nova aquisição do repertório comportamental dos filhos. Como lidar com uma criança que agora é capaz de expressar suas preferências, vontades e sua recusa em cooperar ou aceitar determinadas situações? Assim como a assertividade aparece como uma nova aquisição das crianças ainda pequenas, habilidades parentais como a expressão de opiniões e a solicitação adequada de mudança de comportamento, a negociação e o estabelecimento de regras também podem ser vistas como novas aquisições para os pais nesta etapa do desenvolvimento dos filhos (Cia \& cols., 2006). Segundo Tudge, Hogan e cols. (2000), é possível também que os pais e as mães não interfiram nessas situações por acreditarem ser importante para a criança desenvolver a assertividade e a autonomia, exercendo sua capacidade de decidir e escolher. Corroborando essas idéias, Biasoli-Alves e Caldana (1992) sugeriram que, no Brasil, a partir da década de 1930, houve um aumento no ideário das mães sobre a independência da criança, com conseqüente diminuição do nível de exigência e demandas propostas aos filhos. Nesse sentido, parece que houve uma maior valorização da flexibilidade em detrimento da rigidez e controle parental.

Além disso, de acordo com Kuczynski (1984), parecem existir algumas situações em que a obediência da criança não seria tão essencial e os pais se permitiriam esperar por um momento mais adequado para a criança cooperar. Biasoli-Alves e Caldana (1992) revelaram que parece existir um pequeno número de normas para as quais se exige mais prontamente a obediência da criança, como por exemplo, nas situações envolvendo higiene, saúde ou então frente a comportamentos bastante perturbadores, como os de birra.

Outro dado interessante diz respeito às poucas referências feitas à punição física nos relatos dos pais e mães entrevistados. A idade das crianças é, possivelmente, um fator importante para a compreensão deste dado. Segundo
Dix e cols. (1989), a atribuição de maior ou menor competência e responsabilidade à criança por parte da mãe, também parece mediar as variações nas estratégias disciplinares utilizadas. Nesse sentido, por atribuírem menor consciência, responsabilidade ou culpa a seus filhos, os pais poderiam estar utilizando menos esta estratégia disciplinar. Por outro lado, é interessante observar a frequiência expressiva de explicações, mesmo diante do estágio inicial do desenvolvimento da linguagem em que as crianças se encontram. Vários estudos indicam o uso progressivamente mais freqüente da linguagem na regulação do comportamento infantil, de acordo com o crescimento da criança (McNally \& cols., 1991; Mussen \& cols., 1990; Roberts \& cols., 1984), e os achados deste estudo mostram que já aos 18 meses das crianças, as estratégias verbais de regulação do comportamento infantil aparecem como recurso importante para os pais.

A ausência de diferenças entre as práticas dos pais e das mães entrevistados apóia os achados de Bentley e Fox (1991) e de Weber, Prado, Viezzer e Brandenburg (2004), que também não encontraram diferenças nos estilos parentais com relação a crianças. A semelhança nos relatos das mães e pais encontrada no presente estudo, pode estar indicando que os fatores que influenciam a escolha das práticas educativas, como crenças e valores sobre educação, a experiência com os próprios cuidadores, conflito conjugal (Kanoy, Ulku-Steiner, Cox \& Burchinal, 2003), características da criança e a situação que exige intervenção, parecem ser mais relevantes do que questões de gênero. E, esta explicação pode ser particularmente relevante nestes dois primeiros anos de vida da criança, quando as eventuais divergências entre a mãe e o pai, no modo como concebem a educação do bebê, pode ainda não se expressar em atitudes e comportamentos muito diferentes.

Por fim, o nível socioeconômico também não esteve relacionado às práticas educativas dos pais e mães entrevistados. Wissow (2001), ao utilizar um sistema de classificação de práticas educativas semelhantes ao do presente estudo, com crianças menores de 3 anos de idade, também não encontrou diferenças nem entre famílias de diferentes etnias, nem quanto ao nível socioeconômico.

Já em um estudo brasileiro conduzido por Ribas, Seidl de Moura e Bornstein (2003), tanto a escolaridade materna, como o nível socioeconômico familiar, relacionaram-se a um maior conhecimento sobre desenvolvimento infantil e práticas educativas, ainda que com bebês de 5 meses de idade. Da mesma forma, os estudos de Fox e cols (1995) e de Booth e cols. (1991) encontraram que mães com nível sócio-econômico e educacional inferior tendiam a empregar um menor número de estratégias educacionais e disciplinares não-coercitivas. Um estudo brasileiro (Tudge, Frizzo, Sperb, Piccinini \& Lopes, 2004) também destacou uma possível influência do nível socioeconômico sobre as crenças e valores parentais em pré-escolares, fatores que parecem estar envolvidos com as práticas educativas parentais. Dessa forma, novos estudos são necessários a fim de esclarecer melhor a possível influência deste fator sobre as práticas educativas parentais. 


\section{Considerações Finais}

Os resultados do presente estudo apóiam achados da literatura sobre as mudanças nas práticas educativas decorrentes de modificações no comportamento infantil ao longo do desenvolvimento. Embora o método empregado não permita afirmações conclusivas quanto a essa questão, foram encontradas evidências que indicam o uso freqüente de estratégias que envolvem a linguagem na regulação do comportamento infantil, bem como outras práticas parentais que parecem constituir tentativas de acomodação diante de aquisições recentes do repertório infantil, como por exemplo, a assertividade e a linguagem oral.

Contudo, embora os resultados mostrem que os pais estão reagindo às mudanças no comportamento de seus filhos através do uso freqüente de práticas indutivas, as práticas coercitivas, e especialmente as não-verbais, foram também bastante mencionadas, o que indica que o segundo ano de vida, marcado pelo expressivo desenvolvimento da linguagem na criança, constitui por este motivo, uma etapa de transição para os pais, no que diz respeito à regulação do comportamento infantil.

A ausência de diferenças entre as práticas educativas de mães e pais esteve de acordo com alguns achados relatados na literatura. Juntos esses resultados indicam a menor relevância de questões de gênero na determinação das práticas, se comparadas a outros fatores mais significativos como a situação que exige intervenção, o nível de instrução, a qualidade da relação conjugal ou mesmo a experiência dos pais com seus próprios cuidadores.

O mesmo ocorreu em relação ao nível socioeconômico da família, que no presente estudo não se mostrou associado a diferenças nas práticas educativas. De qualquer forma, a literatura revisada apresenta algumas inconsistências quanto à relação dessas duas variáveis, em particular no que se refere a crianças pequenas (ex. Roopnarine \& cols., 2005). O estudo de Roopnarine e cols. também não encontrou diferenças entre os diferentes níveis socioeconômicos investigados. Mães e pais não diferiram com respeito aos cuidados básicos ou tentativas de estimular e acalmar os bebês, independente do nível socioeconômico investigado, indicando que parece haver mais convergência que divergências entre famílias com crianças dessa faixa etária. Nesta mesma direção, a revisão da literatura conduzida por McLoyd (1998) revelou que estudos realizados com crianças com menos de 3 anos não haviam encontrado necessariamente uma maior prevalência de problemas emocionais e de comportamento entre crianças de nível socioeconômico baixo. Vale destacar, no entanto, que esses dois estudos foram realizados com crianças afro-americanas e por isso pode-se questionar sua validade para o contexto brasileiro. Dessa forma, novos estudos são necessários, especialmente brasileiros, pois ainda há pouca produção sobre esse assunto no país (Ribas \& cols, 2003), principalmente no sentido de esclarecer a eventual extensão com que o nível socioeconômico aparece associado às práticas educativas de mães com crianças pequenas e, o quanto esta relação é mediada por outras variáveis. Além disso, deve-se ressaltar que a amostra desse estudo tinha poucas famílias de níveis socioeconômicos médio-alto e alto. Dada a importância de fatores culturais na determinação das práticas educativas, seria importante que novos estudos utilizassem amostras mais representativas, especialmente levando em consideração possíveis diferenças culturais que podem existir num mesmo centro urbano.

Por fim, cabe destacar a importância de se compreender este momento inicial de socialização da criança na família. A literatura apresenta várias associações entre as práticas educativas e problemas de comportamento em crianças (Patterson, DeGarmo \& Knutson, 2000). Assim ao se investigar as práticas educativas no início da infância pode-se contribuir para a elaboração de estratégias de intervenções precoces que podem prevenir futuros problemas no desenvolvimento infantil e familiar.

\section{Referências}

Alvarenga, P. \& Piccinini, C. (2003). Práticas educativas maternas e a interação entre mães e crianças com problemas de externalização. Aletheia, 17/18, 7-20.

Alvarenga, P. \& Piccinini, C. A. (2001). Práticas educativas maternas e problemas de comportamento em pré-escolares. Psicologia: Reflexão e Crítica, 14(3), 449-460.

Baker, B. L. \& Heller, T. L. (1996). Preschool children with externalizing behaviors: Experience of fathers and mothers. Journal of Abnormal Child Psychology, 24(4), 513-532.

Belsky, J. (1979). Mother-father-infant interaction: A naturalistic observational study. Developmental Psychology, 15(6), 601607.

Bentley, K. S. \& Fox, R. A. (1991). Mothers and fathers of young children: Comparison of parenting styles. Psychological Reports, 69, 320-322.

Biasoli-Alves, Z. M. M. \& Caldana, R. H. L. (1992) Práticas educativas: a participação da criança na determinação de seu dia-a-dia. Psicologia: Teoria e Pesquisa, 8, 231-242.

Booth, C. L., Rose-Krasnor, L \& Rubin, K. H. (1991). Relating preschoolers' social competence and their mothers' parenting behaviors to early attachment security and high-risk status. Journal of Social and Personal Relationships, 8, 363-382.

Chen, X., Rubin, K. H., Cen, G., Hastings, P. D., Chen, H. \& Stewart, S. L. (1998). Child-rearing attitudes and behavioural inhibition in Chinese and Canadian toddlers: A cross-cultural study. Developmental Psychology, 4, 677-686.

Cia, F., Pereira, C. S., Del Prette, Z. A. P. \& Del Prette, A. (2006). Habilidades sociais parentais e o relacionamento entre pais e filho. Psicologia em Estudo, 11(1), 73-81.

Crockenberg, S. B. \& Litman, C. (1990). Autonomy as competence in 2-year-olds: Maternal correlates of child defiance, compliance and self-assertion. Developmental Psychology, 26(6), 961-971.

Dix, T., Ruble, D. N. \& Zambarano, R. J. (1989). Mother's implicit theories of discipline: Child effects, parent effects, and the attribution process. Child Development, 60, 1373-1391.

Dodge, K. A., Pettit, G. S. \& Bates, J. E. (1994). Socialization mediators of the relation between socioeconomic status and child conduct problems. Child Development, 65, 649-665.

Durkin, K. (1995). Developmental social psychology: From infancy to old age. Cambridge: Blackwell Publishers Inc.

Falcone, E. O. (2001). Uma proposta de um sistema de classificação das habilidades sociais. Em H. J. Guilhardi, M. B. B. P. Madi, P. P. Queiroz \& M. C. Scoz (Orgs.), Sobre comportamento e cognição: Expondo a variabilidade (pp. 195-209). Santo André: ESETec Editores Associados. 
Fox, R. A., Platz, D. L. \& Bentley, K. S. (1995). Maternal factors related to parenting practices, developmental expectations, and perceptions of child behavior problems. The Journal of Genetic Psychology, 156, 431-441.

Grupo de Interação social, Desenvolvimento e Psicopatologia (GIDEP). (1998). Ficha de dados demográficos. Instituto de Psicologia - UFRGS, Porto Alegre. Instrumento não publicado.

Grusec, J. E. \& Lytton, H. (1988). Social development: History, theory and research. New York: Springer-verlag.

Hart, C. H., Ladd, G. W. \& Burleson, B. R. (1990). Expectations of the outcomes of social strategies. Relations with socioeconomic status and maternal disciplinary styles. Child Development, 61, 127-137.

Hoffman, M. L. (1991). Commentary. Human Development, 34, 105-110.

Hoffman, M. L. (1979). Development of moral thought, feeling, and behavior. American Psychologist, 34, 958-966.

Hoffman, M. L. (1994). Discipline and internalization. Developmental Psychology, 30, 26-28.

Hoffman, M. L. (1975). Moral internalization, parental power, and the nature of parent-child interaction. Developmental Psychology, 11, 228-239.

Hollingshead, A. B. (1975). Four factor index of social status. Manuscrito não publicado.

Kanoy, K. Ulku-Steiner, B. Cox, M. \& Burchinal, M. (2003). Marital relationship and individual psychological characteristics that predict physical punishment of children. Journal of Family Psychology, 17(1) 20-28.

Kuczynski, L., Kochanska, G., Radke-Yarrow, M. \& GirniusBrown, O. (1987). A developmental interpretation of young children's noncompliance. Developmental Psychology, 23, 799-806.

Kuczynski, L. (1984). Socializations goals and mother-child interaction: strategies for long-term and short-term compliance. Developmental Psychology, 20, 1061-1073.

Laville, C. \& Dionne, J. (1999). A construção do saber. Porto Alegre: Artes Médicas Sul; Belo Horizonte: Editora da UFMG.

McNally, S., Eisenberg, N. \& Harris, J. D. (1991). Consistency and change in maternal childrearing practices and values: A longitudinal study. Child Development, 62, 190-198.

Mussen, P. H., Conger, J. J., Kagan, J. \& Huston, A. C. (1990). Child Development \& Personality. New York: Harper \& Row.

McLoyd. V. C. (1998). Socioeconomic disadvantage and child development. American Psychologist, 53(2), 185-204.

Nachmias, C. \& Nachmias, D. (1996) Research methods in the social sciences. London: Arnold.

Newcombe, N. (1999). Desenvolvimento infantil: Abordagem de Mussen (C. Buchweitz, Trad.) Porto Alegre: Artes Médicas. (Trabalho original publicado em 1996)

Parke, R. D. (1981). Fathering. London: Collins.

Patterson, G. R., DeGarmo, D. S. \& Knutson, N. (2000). Hyperactive and antisocial behaviors: Comorbid or two points in the same process? Development and Psychopathology, 12, 91-106.

Piccinini, C. A \& Alvarenga, P. (2001). Entrevista sobre Práticas Educativas Parentais. Instrumento Não-publicado. Instituto de Psicologia. Universidade Federal do Rio Grande do Sul.
Piccinini, C. A, Castro, E. K., Alvarenga, P., Vargas, S. \& Oliveira, V. Z. (2003). A doença crônica na infância e as práticas educativas maternas. Estudos de Psicologia, 8(1), 75-83.

Piccinini, C. A., Tudge, J. R. H., Lopes, R. C. S. \& Sperb, T. M. (1998). Estudo longitudinal de Porto Alegre. Projeto de Pesquisa não publicado.

Raver, C. C. (1996). Relations between social contingency in mother-child interaction and 2-year-olds' social competence. Developmental Psychology, 32(5), 850-859.

Ribas, R. C. Jr, Seidl de Moura. M. L. \& Bornstein, M. (2003). Socioeconomic status in Brazilian psychological research: II. Socioeconomic status and parenting knowledge. Estudos de Psicologia, 8, 385-392.

Roberts, G. C., Block, J. H. \& Block, J. (1984). Continuity and change in parent's child-rearing practices. Child Development, 55, 586-597.

Robson, C. (1993). Real World Research, Oxford: Blackwell.

Roopnarine, J. L., Fouts, H. N., Lamb, M. E. \& Lewis-Elligan, T. Y. (2005). Mothers' and fathers' behaviors toward their 3- to 4-monthold infants in lower, middle, and upper socioeconomic African American families. Developmental Psychology, 41(5), 723-732.

Saadeh, W., Rizzo, C.P. \& Roberts, D.G. (2002). Spanking. Clinical Pediatrics, 4, 87-92.

Schaffer, H. R. (1996). Social development. Oxford: Blackwell Publishers Ltd.

Siegel, S. \& Castellan, N. J. Jr. (2006). Estatística não-paramétrica para ciências do comportamento ( $2^{\mathrm{a}}$ ed.). Porto Alegre: ArtMed. (Trabalho original publicado em 1988)

Tudge, J. R. H. \& Frizzo, G. F. (2002). Classificação baseada em Hollingshead do nível sócio-econômico das famílias do estudo longitudinal de Porto Alegre: da gestação à escola. Manuscrito não publicado.

Tudge, J. R. H., Frizzo, G. B., Sperb, T. M., Piccinini, C. A. \& Lopes, R. C. S. (2004). Crenças e valores parentais e as atividades da criança como uma preparação para escola. Manuscrito não publicado.

Tudge, J. R. H., Hayes, S., Doucet, F., Odero, D., Kulakova, N., Tammeveski, P., Meltsas, M. \& Lee, S. (2000). Parents' participation in cultural practices with their preschoolers: A cross-cultural study of everyday activities. Psicologia: Teoria $e$ Pesquisa, 16, 1-11.

Tudge, J. R. H., Hogan, D., Snezhkova, I., Kulakova, N. \& Etz, K. (2000). Parents' childrearing values and beliefs in the United States and Russia: The impact of culture and social class. Infant and Child Development, 9, 105-121.

Weber, L. N. D., Prado, P. M., Viezzer, A. P. \& Brandenburg, O. J. (2004). Identificação dos estilos parentais: o ponto de vista dos pais e dos filhos. Psicologia: Reflexão e Crítica, 17, 323-331.

Weber, L. N. D., Viezzer, A. P. \& Brandenburg, O. J. (2004). O uso de palmadas e surras como prática educativa. Estudos de Psicologia, 9, 227-237.

Wissow, L. S. (2001). Ethinicity, income and parenting contexts of physical punishment in a national sample of families with young children. Child Maltreatment, 6(2), 118-129.

Recebido em 02.08.2006

Primeira decisão editorial em 18.10.2006

Versão final em 07.01.2007

Aceito em 07.06.2007 
Anexo. Categorias de práticas educativas parentais (baseadas em Alvarenga \& Piccinini, 2001; Hoffman, 1975, 1994).

\section{Práticas Indutivas}

Negocia e Troca: a mãe ou o pai referia algum tipo de negociação com a criança, conversando com ela, prometendolhe alguma coisa em troca de obediência, oferecendo-lhe alguma alternativa, como uma brincadeira, ou ainda quando os pais referiam entreter a criança.

Explica/Fala: a mãe ou o pai referiam conversar ou explicar algo à criança.

Organiza ambiente: a mãe ou o pai referia utilizar-se de atitudes naturalmente facilitadoras para que a criança tenha sono ou medidas que preparam um hábito na hora de dormir. A utilização desta categoria se deu apenas na situação "hora de dormir".

Comanda verbalmente sem coerção: a mãe ou o pai referia dar ordens ou fazer pedidos à criança indicando o comportamento que deveria ser emitido pela mesma de maneira não aversiva ou coercitiva (punitiva).

\section{Práticas Coercitivas}

Pune: a mãe ou o pai relatava repreender ou xingar a criança, demonstrar desaprovação frente ao seu comportamento, proibir verbalmente a criança de fazer algo ou quando dizia utilizar comandos verbais coercitivos, ou seja, dar ordens ou fazer pedidos indicando o comportamento que deveria ser emitido pela criança, porém de forma coercitiva. Incluiuse nessa categoria relatos de utilizar o olhar como repreensão.

Ameaça: a mãe ou o pai referiam dizer para a criança que iriam puni-la, quando relatavam ameaçar a criança caso esta não parasse de se comportar de determinada forma.

Coage fisicamente: a mãe ou o pai referia obrigar ou forçar fisicamente a criança a comportar-se de determinada forma.

Pune fisicamente: a mãe ou o pai relatavam utilizar intervenções físicas que causassem dor na criança.

\section{Não-interferência}

Não se intromete: a mãe ou o pai afirmavam não interferir de nenhuma maneira frente ao comportamento da criança

Segue ritmo da criança: a mãe ou o pai relatavam tentar respeitar o ritmo da criança ao realizar uma ação ou comportamento.

Cede à vontade da criança: a mãe ou o pai relatavam ceder à vontade da criança, ao desistir de fazer com que a criança os obedecesse.

\section{Outras}

Engana: esta categoria foi utilizada quando os pais afirmavam buscar iludir de alguma maneira a criança para que esta realizasse a tarefa desejada.

Deixa para outra pessoa: esta categoria foi empregada quando os pais relatavam não interferir no comportamento de birra da criança, pedindo ajuda ou deixando que a prática educativa fosse realizada por outra pessoa, comumente o cônjuge. 


\title{
IV CONGRESO CUBANO DE EDUCACIÓN, ORIENTACIÓN Y TERAPIA SEXUAL
}

\author{
I Simposio "La Transexualidad en Cuba" \\ III Taller Metodológico de las Cátedras de \\ Sexología y Educación de la Sexualidad
}

I Simposio de Sexología Clínica, y el I Simposio Salud Sexual,

Vulnerabilidades y VIH/SIDA

Data: 15 a 18 de Janeiro de 2008

Local: Palacio de Convenciones de La Habana, Cuba

Informações: www.cpalco.com 